\title{
EL CUERPO Y LOS PELIGROS COTIDIANOS: ORIGEN Y CONSOLIDACIÓN DEL INDIVIDUO HIPERVIGILANTE EN EL IMAGINARIO COLECTIVO
}

\author{
The body and everyday dangers: origin and consolidation of the \\ hypervigilant individual in collective imagination
}

\author{
Raquel Taranilla* \\ * Universitat Oberta de Catalunya \\ raqueltaranilla@gmail.com
}

\section{Resumen}

En la tensión entre seguridad y libertad, vertebradora del liberalismo avanzado, el invento del riesgo cumple un papel esencial, no solo porque resuelve dilemas propios de la gestión pública, sino porque ha penetrado en la esfera privada de los individuos haciendo emerger una nueva subjetividad, que será el objeto de este artículo: la del individuo hipervigilante. Con carácter teórico, este texto desgrana los procedimientos por los cuales, en el seno de la cultura del peligro, la llamada razón actuarial (aquella que pone la estadística al servicio del cálculo de riesgos) transforma la mirada de la medicina sobre el hecho patológico, lo que, a su vez, repercute en el modo como los individuos entienden su cuerpo y los peligros que lo acechan. Así, se concluye que esa nueva subjetividad exige comportamientos prudentes, que no comprometan

Palabras clave

Gobierno del cuerpo Riesgo

Subjetividad Hipervigilancia Imaginario colectivo

\section{Keywords}

Governance of the body

Risk

Subjectivity

Hypervigilance

Collective imagination la seguridad del cuerpo propio y, a menudo, exige también implicarse en la prevención de enfermedades y la promoción de la salud. Además, la medicina actuarial fragmenta el cuerpo y computa los riesgos específicos de cada fragmento, de modo que invita al individuo a conceptualizarse a la manera de un mapa de riesgos. La hipervigilancia se ha asentado ya plenamente en el imaginario colectivo, por lo que es posible identificar su presencia en las producciones culturales contemporáneas. La obra narrativa de Lydia Davis proporciona ejemplos muy ilustrativos del individuo hipervigilante.

\section{Abstract}

In the tension between security and freedom, which is the core of advanced liberalism, the invention of risk plays an essential role, not only because it solves dilemmas of public governance, but also because it has permeated in the private sphere of individuals, making emerge a new subjectivity: the hypervigilant individual. This theoretical article addresses how, within the culture of danger, the so-called actuarial reason (which uses statistics in the calculation of risks) transforms the medical gaze to the pathological fact, what in turn affects the way the individuals understand their own body and the dangers that threaten it. This new subjectivity demands prudent behaviors, which does not compromise the safety of the body, and often it also requires the involvement in disease prevention and health promotion. In addition, actuarial medicine breaks up the body and computes the specific risks of each fragment, what prompts the individual to self-conceptualize as a risk map. Hypervigilance has become fixed in the collective imagination, so it may be identified in contemporary cultural productions. Lydia Davis' narrative provides illustrative examples of the hypervigilant individual.

Taranilla, R. (2018). El cuerpo y los peligros cotidianos: origen y consolidación del individuo hipervigilante en el imaginario colectivo. Papeles del CEIC. International Journal on Collective Identity Research, vol. 2018/1, papel 185, CEIC (Centro de Estudios sobre la Identidad Colectiva), UPV/EHU Press, http://dx.doi.org/10.1387/pceic.17727 


\section{Peligros Cotidianos}

A tenor de las estadísticas, la probabilidad de morir en un accidente de tráfico es extraordinariamente mayor que la de morir en un siniestro aéreo. Por eso, el miedo a volar es un miedo infundado: hay razones de peso para sostener que desplazarse en avión es el modo más seguro de viajar, y en esos argumentos encuentra sosiego el protagonista de la novela El libro de Esther (Méndez Guédez, 1999), que empieza así:

"Por cada trescientos cuatro mil carros que se estrellan en las carreteras apenas se cae un avión. Por cada seiscientos veinte mil motocicletas que se voltean en las carreteras apenas se cae un avión. Por cada dos millones de autobuses que se trituran, se deslizan, se desarman, se golpean, por cada dos millones de ellos que explotan, tan sólo se cae un avión. Las cifras son claras, las cifras no mienten. Tendría entonces que formarse allá en la tierra una orgía de carros, motocicletas y autobuses embistiéndose, dando vueltas, incendiándose, estallando en medio de nubes de humo y gasolina, abriendo en dos las centrales nucleares, quebrando represas, aplastando cuarteles del ejército, para que se justifiquen como verdaderamente preocupantes los brincos salvajes, los brincos de caballo enfermo que abruman a este DC 10.

Lo explico para que el señor anciano que tengo a mi lado y se aferra al asiento logre tranquilizarse y beba al fin su jugo de manzana. Lo explico para que las aeromozas dejen de correr de un lado a otro mientras una voz quebrada nos dice por los parlantes que todo marcha bien y se les agradece a los señores pasajeros mantener abrochado el cinturón de seguridad.

Pero nadie me oye.

A la gente le fascinan las emociones fuertes, la angustia, el delirio. Supongo que en medio del aburrimiento de sus vidas les gusta tener algo miserable en qué pensar, algo terrible a lo cual enfrentarse.

Yo no. Por lo general estoy tranquilo. Tomo mis vasos de té frío, camino cuatro kilómetros diarios, evito comer sesos o hígado, y jamás, jamás bebo ninguna clase de licor que al permanecer siete segundos en la boca me deje las mucosas irritadas."

La calma del protagonista no se limita a su modo de encarar las turbulencias del vuelo, sino que se extiende a su vida en general: vigila lo que bebe y también lo que come, y hace además ejercicio moderado. 
Sigue, por tanto, unas pautas de conducta a las que se suele considerar garantía de una vida larga y sana, con las que busca proporcionarse una existencia apacible. Tanto las razones que maneja como las decisiones que toma a la hora de gobernar su cuerpo resultan, a los ojos del lector actual, absolutamente familiares. El narrador piensa y gobierna su propio cuerpo y los peligros que lo amenazan empleando una lógica aprendida en los medios de comunicación, en campañas institucionales, en consultas médicas, en el colegio: una lógica que establece las normas de la gestión prudente de uno mismo, de cara a paliar - o, al menos, minimizar - los peligros que lo acechan. Justo en el extremo opuesto, como ejemplar de un ser abyecto, imprudente hasta lo insoportable, situariamos a la joven que cuenta su historia en una reunión de Alcohólicos Anónimos, en la novela La broma infinita:

"[O]tra novata, una chica rechoncha y sonrosada sin pestañas y con los dientes estropeados de fumar cocaína, se levanta y habla con el acento sin erres del sur de Boston sobre el hecho de estar embarazada a los veinte años y de fumar piedras de cocaína de forma endiablada aunque sabía que le hacía mal al bebé y pese a que ella quería dejar de fumar con todas sus fuerzas. Habla de romper aguas y del dolor de las contracciones en mitad de la noche y en una pensión para indigentes en plena fumata para cuyo pago se había tenido que pasar la tarde perpetrando triquiñuelas increíblemente sórdidas y degradantes; hacía cualquier cosa por drogarse, dice, incluso preñada, dice." (Foster Wallace, 2002: 428).

La oposición sujeto prudente/temerario proporciona una escala de valoración de primer orden con la que juzgamos hoy en día el gobierno que cada cual hace de sí mismo. Ese juicio a la autogestión, que incluye siempre apreciaciones morales, gravita en torno al campo magnético que crea la idea de peligro, que es uno de los centros neurálgicos de la arquitectura del sistema liberal. Según advirtiera Foucault (2009: 73-74), el liberalismo se mantiene en un juego de contrapesos entre la creación de libertad y de seguridad, que son dos tendencias antinómicas que se contrarrestan gracias a la noción de peligro. En ese sentido, por poner un ejemplo, el ideario liberal entiende que la libertad del individuo para vender bienes merece limitarse si tales bienes representan un peligro para los demás. 
El par libertad-seguridad no solo regula el ámbito público sino que, en tanto que útil biopolítico, penetra y se instala en la esfera privada, habilitando a todo individuo a pensar su existencia en un debate íntimo entre ejercer plenamente su libertad y velar por su seguridad. Esa ponderación se resuelve computando las amenazas que se ciernen sobre el cuerpo, en un proceso que se repite continuamente, pues los peligros de la vida diaria son numerosos:

"En el siglo XIX aparece toda una educación del peligro, toda una cultura del peligro que es muy diferente de esos grandes sueños o esas grandes amenazas apocalipticas como la peste, la muerte, la guerra, de las que se alimentaba la imaginación política y cosmológica de la Edad Media e incluso del siglo XVII. Desaparición de los jinetes del Apocalipsis y, al contrario, aparición, surgimiento, invasión de los peligros cotidianos, peligros cotidianos perpetuamente animados, reactualizados, puestos en circulación, entonces, por lo que podríamos llamar cultura del peligro en el siglo XIX, con toda una serie de aspectos. Tómese, por ejemplo, la campaña de inicios de ese siglo sobre las cajas de ahorro, véase la aparición de la literatura policiaca y el interés periodístico por el crimen a partir de mediados del siglo XIX; véanse todas las campañas relacionadas con la enfermedad y la higiene" (Foucault, 2009: 75).

En la cultura del peligro no basta con apuntar hacia zonas oscuras y señalar entidades que temer. Desde su surgimiento, la cultura del peligro se ha ido sofisticando; el entramado conceptual y procedimental involucrado es cada vez más complejo y ha generado, tal como propone este artículo, una subjetividad específica, la del individuo hipervigilante, que ya está integrada en el imaginario liberal. En tanto que individuo hipervigilante, el protagonista de El libro de Esther (Méndez Guédez, 1999) no solo identifica los diversos peligros a los que hace frente, sino que es capaz de poner en marcha un razonamiento refinado sobre el riesgo real de sufrir un daño y los modos de prevenirlo.

Si la cultura del peligro ha alcanzado la médula de nuestro sistema de gobierno ha sido precisamente a través de la noción de riesgo, invento al que estará destinado el apartado 2 de este artículo. El apartado 3 se ocupará del modo como el riesgo se ha convertido en un resorte para crear conocimiento $y$, concretamente, conocimiento médico. El apartado 4 abordará la emergencia del individuo hipervigilante como subjetividad específica del liberalismo avanzado, cuya acción se orienta 
a la gestión prudente del cuerpo y que, en aquellas ocasiones en que más se sofistica, está alimentada por el cálculo de riesgos. Finalmente, el apartado 5 propondrá la producción literaria de Lydia Davis como ejemplo de la recepción cultural de esa nueva subjetividad en el ámbito de la ficción.

\section{EL INVENTO DEL RIESGO}

Tan definitorio es el riesgo del momento histórico actual que, de hecho, se habla de la segunda modernidad como de una sociedad del riesgo (Beck, 2002) para aludir al momento en que el ser humano se percata de que el progreso encierra en sí mismo, de forma indefectible, amenazas que ponen en peligro el futuro global ${ }^{1}$. Ahora bien, para explicar la emergencia de la idea de riesgo es necesario retrotraerse varios siglos, al momento en que el comercio marino empieza a conquistar los mares del mundo. Comúnmente se acepta que el origen del término riesgo está en la forma risco, con la que originariamente se hacía referencia a las rocas, a los peñascos escarpados con que los barcos de los exploradores y los comerciantes europeos corrian el peligro de toparse cuando surcaban aguas lejanas. Con el tiempo el término pasó a contener solamente la idea de peligro: primero, de un peligro en el mar (como una tempestad o un abordaje pirata) y, luego, de cualquier tipo de peligro. Como apunta Giddens (2000: 33-34), el riesgo surge como un peligro real en un espacio desconocido y posteriormente su significado se va orientando hacia el futuro, a través de la metáfora "el porvenir es tierra ignota": un riesgo es el peligro que amenaza desde el futuro.

El desarrollo de la estadística (que adquiere madurez en el siglo XVIII) supuso un paso fundamental en la invención del riesgo en su sentido actual, pues el término incorpora entonces su rasgo conceptual definitivo, que es el cálculo de probabilidades acerca de que un evento ocurra efectivamente o no. La situación concreta en que emerge la idea

\footnotetext{
${ }^{1}$ La noción de riesgo se ha convertido una de esas categorías estrella en las caracterizaciones del mundo contemporáneo y, por ello, está en el centro de la obra de un número destacado de autores cuyas propuestas son a veces incompatibles. Véase, para una nómina de esos autores y de los diferentes enfoques sobre el riesgo, Garland (2003). Entre ellos, quienes han merecido mayor atención desde las ciencias humanas han sido Ulrick Beck y Anthony Giddens (que plantean la centralidad del riesgo en las dinámicas sociales de la modernidad, en el nivel del orden mundial), a Mary Douglas (desde el campo de la antropología cultural) y a Michel Foucault y algunos de sus continuadores, como François Ewald (interesados en el análisis histórico de la razón gubernamental).
} 
moderna del riesgo, según cuenta Foucault (2006: 76-83), sucede a lo largo del siglo XVIII en relación con el tratamiento de la viruela. La generalización de la vacuna contra la viruela posibilitó la pregunta sobre la probabilidad de que un individuo desarrolle la enfermedad para el caso de que esté o no inmunizado, cuestión que encierra una nueva mirada sobre el hecho patológico: la medicina ya no se ocupa de los cuerpos enfermos individuales, sino que adquiere entonces las herramientas necesarias para encarar la enfermedad en su amplitud social. La viruela fue el primer mal cuya incidencia se planteó en relación con determinados grupos de población y con el riesgo de contraerla.

Nace entonces un modo de pensar la sociedad que articulará el gobierno propio del estado moderno (Ewald, 1986), que rápidamente encuentra en la demografía - gracias a las herramientas estadísticas - un proyecto que le va a permitir radiografiar a la sociedad según infinitas variables. La natalidad y la mortalidad, las enfermedades y los delitos, la productividad de las industrias y el abandono escolar comienzan a contabilizarse, haciendo uso de la idea de que es posible pensar a los individuos en relación con unidades sociales mayores $y$, de ese modo, establecer patrones de distribución de características, comportamientos, etc. El razonamiento demográfico, al inscribir al individuo en un grupo poblacional, permite que el ejercicio de gobierno pueda trascender el dominio del individuo e incorpore el aparato conceptual que le capacite para encarar también la regulación de agregados de población (Foucault, 2009), que es el objetivo consustancial a la sociedad de control, que implica, entre otras cosas, el paso del individuo-cuerpo a la cifra (Deleuze, 1999).

Valiéndose de métodos probabilísticos cada vez más complejos, las ciencias sociales, la medicina, la criminología, la pedagogía, etc., van a ir generando saberes que no solo se proponen describir la sociedad del presente de manera minuciosa, sino que también buscan pronosticar el futuro, que empieza a pensarse como un objeto previsible y cuantificable, y, aún más, un objeto sobre el que se puede intervenir. EI mito moderno de la calculabilidad (Reddy, 1996) afianza la fe por avistar la tierra ignota que es el futuro, poder cartografiarla e incluso poder modificarla. Eventos como la enfermedad, el crimen o los accidentes laborales pasan a ser concebidos como riesgos cuya distribución particular entre las poblaciones permite hacer previsiones y plantear medios de prevención. El descubrimiento de fondo en este punto es que 
es posible establecer regularidades no solo en la normalidad, sino también en las desviaciones que se dan en el seno de los grupos poblacionales: esto es, que las características y los comportamientos desviados no son aleatorios, sino que, con los instrumentos oportunos, es posible identificar patrones y reglas que rigen el desvío.

Gracias al cálculo de probabilidades, el concepto de riesgo gana el músculo necesario para convertirse en motor de la razón del liberalismo económico, que impone un cómputo orientado al futuro en términos de ganancias y de pérdidas. Su vigor procedimental hace que desde el ámbito empresarial se extienda a otros campos e incluso alcance la organización de la vida privada. De ese modo, en el ideario propio del régimen liberal, la identificación de peligros y de su nivel de riesgo aparejado funciona proporcionando las razones que mueven a los individuos a contratar un seguro de vida, a usar preservativo, a dejar de fumar, a hacer deporte o a instalar en casa un sistema de alarma antirrobo. En efecto, el invento del riesgo provoca la aparición de una serie de tecnologías del riesgo, que incluyen, por ejemplo, las mutualidades de asegurados (esto es, los seguros contra todo tipo de eventualidades) o la rama del derecho que se conoce como derecho de daños. Ese lugar destacado del riesgo llega incluso a ser definitorio del sistema de gobierno: así, el estado del bienestar merece, tal como demuestra Ewald (1986 y 1991), entenderse no como un sistema de redistribución de rentas, sino fundamentalmente como un sistema de colectivización de riesgos. En el ámbito de la salud y, en general, de la gestión corporal, el riesgo no solo es el sustento teórico de la medicina preventiva, sino que además hace irrumpir una nueva subjetividad, una representación particular del yo en peligro (Nettleton, 1997).

\section{LA RAZÓN ACTUARIAL EN LA PRODUCCIÓN DE SABER MÉDICO}

Es en la industria de los seguros y la de las finanzas, que se fundamentan en la técnica actuarial (que consiste en emplear la estadística a la predicción de riesgos), donde se han consolidado un saber y un modo de razonamiento que son vertebrales en la cultura del peligro. Su extensión al campo de la gestión humana ha llevado a hablar del control actuarial de las poblaciones, lo que ha motivado en las últimas décadas estudios críticos, sobre todo en relación con sus implicaciones en la administración de justicia y la criminología (Ericson y Haggerty, 1997; Feeley y Simon, 1994; Garland, 2005; Harcourt, 2007; Logan, 2000; Mary, 
2001; O'Malley, 1998; San Martín, 2009). Tales estudios, en cambio, no tienen equivalentes en la medicina, pese a que la razón actuarial aporta el método fundamental a través del cual la investigación en ciencias de la salud aprehende la noción de peligro, la objetiva y la pone al servicio de sus prácticas. De hecho, la razón actuarial se ha vuelto imprescindible en la disciplina médica (Dawes, Faust y Meehl, 1989) y, en particular, en las ramas de la epidemiología y la medicina predictiva, lo que ha llevado a hablar de una "epidemia del riesgo" en la ciencia médica (Skolbekken, 1995).

Véase el texto siguiente como muestra del modo como la investigación médica hace uso de la razón actuarial a la hora de generar saber. El texto pertenece a las conclusiones de un estudio (Smyk et al., 2012) sobre el papel de los factores ambientales y la predisposición genética en el desarrollo de la cirrosis biliar primaria²:

\section{"Individuos en riesgo de desarrollar CBP [Cirrosis Biliar Primaria]}

En una jerarquía de riesgos que predisponen al desarrollo de $\mathrm{CBP}$, el más importante es el parentesco, especialmente en mujeres familiares de un paciente de CBP: las hijas y las hermanas de pacientes de CBP son quienes tienen un riesgo mayor. El riesgo probablemente es mayor en sujetos con un historial de exposición al humo del tabaco o con un historial de ITU [Infección del Tracto Urinario] recurrente. Se debería incentivar entre estos individuos el control de AAM [Anticuerpos Antimitocondriales], dado su valor predictivo. Una cuestión esencial es a qué edad y con cuánta frecuencia estos individuos deberian someterse a controles. En relación con el tratamiento de la CBP, las directrices norteamericanas y europeas actuales no proporcionan un itinerario claro para la intervención sobre el grupo de individuos predispuestos a la enfermedad. En la CBP familiar, las generaciones posteriores tienden a desarrollar la enfermedad a una edad más temprana y, en algunos casos, su progresión es más agresiva. Se necesitan mayores esfuerzos para establecer los criterios que determinen qué individuos deben ser controlados, cuándo iniciar los controles y con qué regularidad deben hacerse. Lo que está claro es que hay un subgrupo de pacientes de CBP que nunca desarrollarán la enfermedad hepática hasta sus estadios finales, pero que serán afectados por los sintomas de la CBP, como el prurito y la fatiga. Identificar a estos individuos permitirá un tratamiento

\footnotetext{
${ }^{2}$ La traducción es nuestra. 
temprano y a medida. Aunque se han atribuido algunos riesgos al uso de tintes para el cabello, esmaltes de uñas y otros cosméticos, no está claro si suponen un riesgo verdadero: puede ser prematuro y contraproducente recomendar que se evite su uso. Se necesitan más investigaciones sobre el rol de los estrógenos." (ibídem: 206207).

La meta del estudio es establecer un grupo poblacional en riesgo de desarrollar CPB, esto es, un conjunto de individuos que, dadas sus características (ser hijas o hermanas de pacientes de CBP, o tener un historial de exposición al humo de tabaco o de infección urinaria), corren un riesgo mayor que el normal de sufrir la enfermedad. El grupo de riesgo supone una desviación de la norma que conviene corregir, de modo que ello justifica proponer una medida de prevención: "Se debería incentivar entre estos individuos el control de AMA, dado su valor predictivo". La identificación de un nivel de riesgo superior al de la normalidad es, por tanto, una razón para la intervención clínica. En el lado contrario estarían aquellos factores que no han podido vincularse a un aumento del riesgo (el uso de tintes de cabello, etc.) y que, consecuentemente, no permiten identificar un grupo de riesgo ni establecer una política de prevención.

La investigación médica recurre al cálculo del riesgo como instrumento para ordenar a la población general y determinar conjuntos de individuos para los que poder pensar protocolos de actuación que rijan su gobierno. En ese sentido, la mirada actuarial sobre el hecho patológico se dirige a tres instancias a las que se hace dialogar permanentemente: la población general, el grupo de riesgo y el individuo. A la hora de tratar a un paciente concreto, la clínica le pone en relación con el grupo de riesgo al que pertenece y entonces decide cómo tratarle. El fragmento siguiente pertenece a las conclusiones de una investigación (Liede, Karlan y Narod, 2004) sobre la relación entre cierta mutación genética y el desarrollo de determinados cánceres ${ }^{3}$ :

"Los criterios para testar [la mutación de los genes BRCA1 y BRCA2] en los hombres deberían ser similares a los criterios para examinar a las mujeres. Debería considerarse someter a tests genéticos a los hombres sin cáncer en el caso de que en su familia haya precedentes de cáncer de pecho o de ovarios (en primer $o$ en segundo grado familiar, y en cáncer

\footnotetext{
${ }^{3}$ La traducción es nuestra. 
diagnosticado antes de los 50 años). Los hombres diagnosticados de cáncer de pecho deberían ser sometidos a un test, independientemente de su historia familiar [...]. Los hombres descendientes de judios askenazies deberian considerar el test genético con criterios menos estrictos, dado que la mutación tiene una prevalencia del $2.5 \%$ en la población total de judíos askenazíes." (ibídem: 740).

De entre el conjunto de la población masculina, el estudio selecciona tres subconjuntos (los hombres sin cáncer pero con familiares enfermos de cáncer de pecho u ovarios, los hombres con cáncer de pecho, y los descendientes de judios askenazies) y recomienda practicarles un test que determinará sus probabilidades de desarrollar cáncer. El razonamiento que llevan a cabo la investigación y la práctica médica traza líneas que sitúan al individuo entre otros con condiciones y destinos similares, en un procedimiento analítico y de decisión que será determinante en el modo como cada persona piensa su cuerpo y lo gestiona, según se expondrá más adelante. Ahora bien, ese cruce entre las instancias de actuación (individual-grupal-poblacional) no solo se filtra en el universo del individuo particular sino que también emerge en el discurso científico. Muestra de ello es el título de la publicación previa sobre la predisposición para sufrir cirrosis, que traducido al español sería este: "Autoinmunidad y entorno: ¿estoy en riesgo?". Esa pregunta en primera persona del singular (que es llamativa en el discurso científico, que se pretende objetivo e impersonal) simula la voz de un individuo cualquiera, de un miembro indeterminado de la población que se pregunta por su pertenencia al grupo en riesgo de enfermar de cirrosis. De ese modo se pone en evidencia que, aunque la literatura médica se limite en apariencia a abordar las tendencias distribucionales de una enfermedad en una operación que afecta a lo poblacional, su poder tiene un alcance y un calado individual $y$, en el fondo, se sabe poseedora de un efecto en la composición de las subjetividades. El conocimiento médico creado acerca de los riesgos que tienen los cuerpos de desarrollar enfermedades merece, por tanto, ser integrado en esa red difusa de instancias de gobierno desde la que se ejerce una dominación pluriforme y a menudo incoherente, pero que tiene su traducción y su peso en las lecturas y las decisiones que cada individuo impone a su existencia. El apartado siguiente se dedica, precisamente, a la línea que une el conocimiento médico actuarial y ciertas prácticas prudentes del individuo hipervigilante. 


\section{LA CONCIENCIA DE RIESGO EN LA GESTIÓN DEL CUERPO}

Hay quien habla de la sociedad liberal avanzada como de una época neoprudencialista (Sepúlveda, 2011) porque en ella el buen ciudadano se comporta prudentemente y decide con libertad respetar las normas, por el bien propio y ajeno. Dicho de otro modo, ante un dilema entre libertad y seguridad, la ideología neoprudencialista induce al individuo a tomar una decisión que evite riesgos y, es más, que suponga una lucha activa contra ellos. En el seno del neoprudencialismo ha emergido la figura del homo prudens (O'Malley, 1996), el individuo que recurre al mercado para abastecerse de bienes que satisfagan "sus necesidades vitales de seguridad, placer y bienestar personal y existencial" (De Marinis, 1999: 94) y que, además, se implica en una estrategia personal para reducir el riesgo al mínimo. El neoprudencialismo, por citar un ejemplo, ha sido terreno para que florezca una industria dedicada a la protección doméstica de los niños, para la que no se escatiman recursos (Katz, 2001).

Frente al individuo prudente se situaría todo aquel que ningunea los riesgos, asumiéndolos, pero sobre todo aquel que se comporta de forma imprudente, incrementando con temeridad sus probabilidades de sufrir daños. Se trata de otra subjetividad generada en torno a la idea de peligro, que también debe ser entendida como una reacción a la centralidad del riesgo en las prácticas de gobierno pero que es de signo opuesto a la del hombre y la mujer prudentes. Su análisis ha sido abordado en relación con las "prácticas extremas" (como equivalente del inglés edgework) y se ha descrito como subjetividad vinculada a los deportes de riesgo, el crimen o determinadas prácticas sexuales consideradas no seguras (Lyng, 1990 y 2005). Aquellas personas cuyos comportamientos se consideran peligrosos son llamadas a reconvertirse, a hacer elecciones que se consideren racionales y morales. En ese sentido, se generan políticas de prevención que recurren al razonamiento de tipo actuarial para establecer mecanismos de intervención para reducir o eliminar comportamientos peligrosos (Castel, 1991). Las diferentes instancias de gobierno del liberalismo avanzado cumplen, en ese escenario, un papel de apologetas de la prudencia que, recurriendo a la cuantificación de peligros, dotan a sus ideas de una base argumental que funciona sólidamente. El ámbito de la salud resulta idóneo para hacer encomio de la prudencia. De hecho, la medicina puede ser vista como una empresa pedagógica y moralizadora 
(Lupton, 1993; Massé, 1999), que recurre, entre otros, al saber actuarial para apuntalar su dominio.

Como se apuntó previamente, el conocimiento médico sobre riesgos no solo tiene como receptor la comunidad científica, sino que alcanza la esfera del individuo lego en medicina, pero con una cantidad ingente de informaciones sobre los riesgos que amenazan su cuerpo $y$, asimismo, sobre los recursos para combatir peligros. De una parte, las políticas de salud pública se construyen en torno a un peligro que se calcula en términos de riesgo y se pone a funcionar a fin de que los propios individuos se comprometan en la gestión de su cuerpo. Ejemplo de ello son los índices de masa corporal, que fundamentan la construcción social de la idea de obesidad y el riesgo asociado de desarrollar enfermedades coronarias: para combatir la obesidad se pone al alcance de los individuos una batería de técnicas que proporciona el mercado (en forma de alimentos específicos, prácticas deportivas, etc.). De otra parte, el conocimiento de la medicina alcanza al individuo fundamentalmente a través de los medios de comunicación, que divulgan el saber médico especializado y a menudo proponen recomendaciones de vida sana a partir de conclusiones sanitarias que se mezclan con ideas sobre el cuerpo de origen y condición muy diversos.

La credibilidad de la información sanitaria viene sustentada, primeramente, por la autoridad que se le asigna a la labor científicomédica y, además, por cierto fetichismo de los números que hace de los resultados que arroja la razón actuarial herramientas de control extraordinariamente potentes. En la ideología del riesgo se asume que la naturaleza pone a las personas en peligro y se presenta la ciencia como salvífica, como esa instancia correctiva del estado natural que proporciona recetas para paliar los riesgos de la vida salvaje ${ }^{4}$. Ese relato de la ciencia benefactora se ha filtrado, de hecho, en el imaginario colectivo y explica, por poner un caso aparentemente alejado del ámbito de la salud, que en los relatos de superhéroes a menudo se dé que el superhéroe disponga de un don natural que entraña una amenaza para él o para el mundo y deba, en consecuencia, aprender a manejarlo usando herramientas o saberes que le proporciona la ciencia.

\footnotetext{
${ }^{4}$ No obstante, esa visión amenazante de la naturaleza convive con la contraria: con el mito de la naturaleza como lugar beatífico y protector que la ciencia y la técnica corrompen, dañando con sus prácticas depredadoras el medioambiente $y$, con ello, poniendo en riesgo la vida humana.
} 
Es evidente que la prudencia tiene un encaje extraordinario en esa ideología de la salud que, en inglés, se ha dado en llamar healthism (Crawford, 1980) y que emerge en EEUU durante la década de 1970, colocando el bienestar corporal en el centro de la identidad humana. Los individuos se vuelven responsables de su salud y se atribuyen un rol activo y consciente en el proyecto de "ciudadanía saludable" (Sharon, 2014). Inicialmente vinculada a la medicalización, la ideología de la salud ha ido expandiendo su dominio, saliendo fuera de la clínica y conformando un modo de vida (Turrini, 2015) que ha colonizado tanto el discurso público como el privado con tal calado que resulta difícil mantenerse al margen de la doctrina del cuidado al cuerpo, tanto si se acata como si se reacciona contra ella. Su dogma es divulgado por las autoridades médicas y también desde la administración pública (en campañas de promoción de la salud) y los medios de comunicación (Førde, 1998), que animan a la ciudadanía a adoptar conductas de vida sana y a emplear para ello bienes y servicios que proporciona el mercado. El ciudadano prudente, que ha interiorizado las normas sanitarias y las ha convertido en un código de autocontrol (Petersen y Lupton, 1996), es en última instancia un consumidor de bienestar. En ese sentido, el riesgo y la prudencia conforman un sistema que, en términos de Foucault, merece ser calificado como una tecnología del yo, pues permite a los individuos "efectuar, por cuenta propia o con la ayuda de otros, cierto número de operaciones sobre su cuerpo y su alma, pensamientos, conductas, o cualquier forma de ser, obteniendo así una transformación de sí mismos con el fin de alcanzar cierto estado de felicidad, pureza, sabiduría o inmortalidad" (Foucault, 1990: 48).

Ahora bien, conviene advertir el error teórico que conlleva la aplicación directa de las descripciones actuariales de enfermedades a la esfera particular. El poder de la razón médica actuarial se limita a poder decir qué grupo de individuos tiene un riesgo de sufrir cierto mal que es mayor que el normal. Dado que maneja datos grupales, el cálculo actuarial solo arroja resultados grupales, que solo falazmente pueden emplearse en una lectura individualizada. De hacerlo, se incurre en una falacia estadística, la falacia ecológica, que consiste en llegar a conclusiones sobre individuos a partir de las estadísticas del grupo al que dichos individuos pertenecen (Piantadosi, Byar y Green, 1988). Y, sin embargo, esa trasposición ilícita de lo grupal a lo individual es permanente en las técnicas de gobierno presentes, sobre todo, cuando se divulgan de 
forma gruesa los resultados de investigaciones científicas. Igual que la criminología crítica ha alertado contra los procesos de profiling (en español "perfilación"), que consisten en establecer el grado de peligrosidad de un individuo atribuyéndole la probabilidad de cometer un delito en función de su pertenencia a un grupo (Harcourt, 2007), convendría abstenerse de atribuir perfiles sanitarios que traspongan al individuo características identificadas en el nivel del grupo.

Pese a ello, entre los componentes distintos que están implicados en la comprensión de los peligros que acechan el cuerpo y mueven a adoptar comportamientos prudentes, la razón médica actuarial ocupa un lugar destacado $y$, como se dijo arriba, se considera particularmente cualificada. Eso es así porque apelando al riesgo grupal se crea en el individuo una falsa sensación de conocimiento matemático sobre el cuerpo que le anima a confiar acríticamente en pautas de prevención. Es más, puesto que la lógica actuarial devuelve una representación del cuerpo "fragmentado en múltiples datos" (San Martín, 2009: 58) y procesado en virtud de riesgos específicos, el individuo acaba por representar su propio cuerpo como si compusiese un mapa de riesgos. La técnica del mapa de riesgos, que nació en Italia hacia 1960 en una fábrica de automóviles Fiat, surgió como iniciativa sindical a fin de concienciar a los trabajadores de los riesgos que asumían operando en las cadenas de montaje; empleando planos de la fábrica y lápices de colores, los propios trabajadores identificaban peligros y los ubicaban en el espacio, lo que les hacía conscientes de las amenazas del entorno fabril (Mujica, 1992). La técnica del mapa de riesgos, que se ha extendido y generalizado en la prevención de riesgos laborales, tiene una analogía en el modo como los individuos piensan su propio cuerpo, fragmentado en órganos y sistemas susceptibles de enfermar en una probabilidad determinada. En ese sentido puede llegar a entenderse la idea de Beck (2002: 5) de que el riesgo nos proporciona un mapa cognitivo que nos permite colonizar el futuro. El riesgo, efectivamente, nos da argumentos para componer una cartografía de nosotros mismos que nos asiste en el autogobierno.

Aunque la medicina genera una parte nada desdeñable del conocimiento que sirve para gestionar los cuerpos, la clínica se retira, al menos en apariencia, de parte de la decisión última sobre los tratamientos. Se espera $y$, de hecho, se estimula que los pacientes tengan un papel activo y principal en la promoción de su salud y la 
gestión de la enfermedad, mientras que los médicos se reinterpretan como expertos que no ordenan sino que recomiendan (Defossez, 2016). $y$, sin embargo, por encima de los procesos de subjetivización y aparente empoderamiento, nunca deja de interferir la autoridad del médico. Tomemos como muestra un fragmento del cómic Píldoras azules (Peeters, 2004), que cuenta la historia de amor entre Frederik y Cati, una chica seropositiva. Ocurre que, en determinado momento, Frederik necesita acudir al médico con urgencia: tiene un corte profundo en el dedo $y$, tras practicar sexo con su amada, cree posible haberse infectado. Como en otras ocasiones, está aterrado. Pero esta vez el doctor le sorprende con información nueva y una recomendación desconcertante, según puede leerse en el fragmento transcrito tras las imágenes:

\section{Imagen 1. Peeters (2004: 136)}
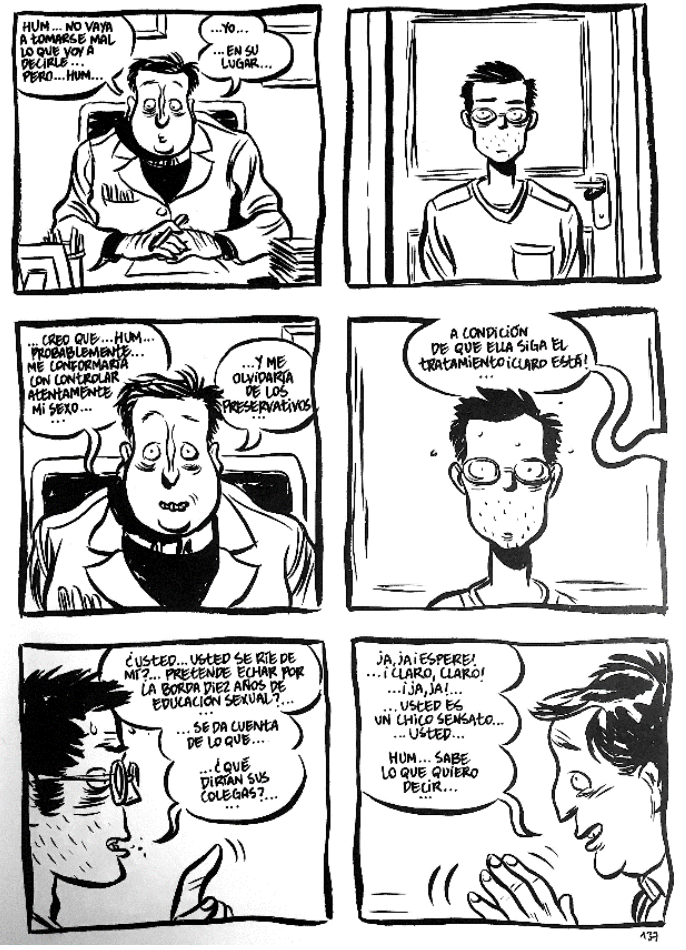
Imagen 2. Peeters (2004: 137)
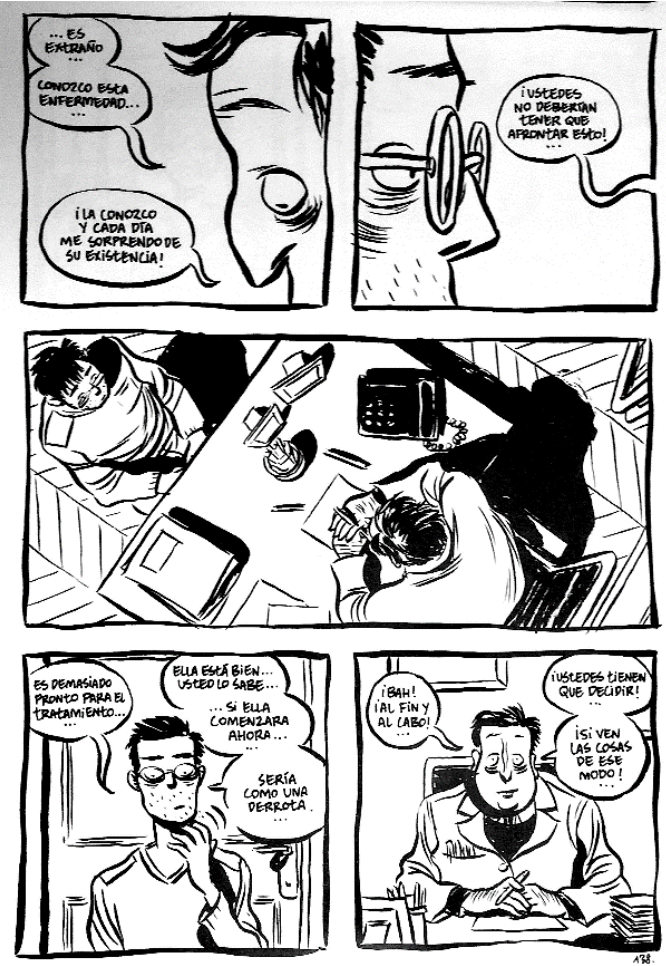

Imagen 3. Peeters (2004: 138)
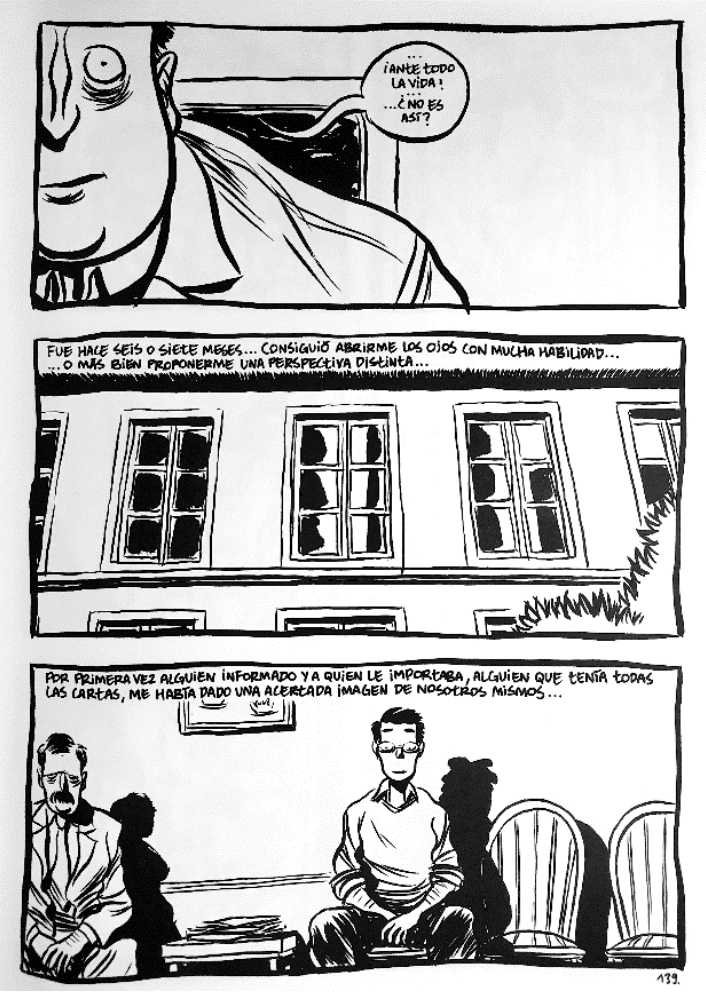

Papeles del CEIC

http://dx.doi.org/10.1387/pceic. 17727 
"-Es una buena chica... Lo sabe... Una chica encantadora...

- ¿Perdón?

-Su amiga...

- ¡Ah! Sí, lo sé.

-Tiene suerte... ¡Los dos la tienen!

-Mm... No siempre es fácil. Pero no se me olvida...

-Hum... No vaya a tomarse mal lo que voy a decirle... pero... hum... yo... en su lugar... creo que... hum... probablemente... me conformaría con controlar atentamente mi sexo... y me olvidaría de los preservativos... a condición de que ella siga el tratamiento, ¡claro está!...

— ¿Usted... usted se ríe de mí?... ¿Pretende echar por la borda diez años de educación sexual?... Se da cuenta de lo que... ¿Qué dirían sus colegas?...

—Jaja. ¡Espere!... ¡Claro, claro!... ¡Jaja! Usted es un chico sensato... Usted... Hum... sabe lo que quiero decir... Es extraño... Conozco esta enfermedad... ¡La conozco y cada día me sorprendo de su existencia! ¡Ustedes no deberían tener que afrontar esto!

-Es demasiado pronto para el tratamiento... Ella está bien... Usted lo sabe... Si ella comenzara ahora... sería como una derrota.

— ¡Bah! ¡Al fin y al cabo, ustedes tienen que decidir!... ¡Si ven las cosas de ese modo!... ¡Ante todo la vida!... ¿No es así?...

Fue hace seis o siete meses... Consiguió abrirme los ojos con mucha habilidad... o más bien proponerme una perspectiva distinta... Por primera vez alguien informado y a quien le importaba, alguien que tenía todas las cartas, me había dado una acertada imagen de nosotros mismos." (ibídem: 136-138).

El diálogo entre Frederik y el doctor se resuelve con un cambio de concepción del protagonista respecto de su cuerpo y del riesgo que asume con sus prácticas. En contra de la información de las campañas de prevención del VIH, que prescriben el empleo del preservativo como práctica de sexo seguro, el doctor instruye a Frederik en una práctica de sexo seguro alternativa (que le permite, para empezar, abandonar la protección del preservativo, aunque exige que su pareja se someta a un tratamiento médico específico). Esa novedad contradice las pautas sanitarias que Frederik ha recibido durante años y que sigue diariamente con obsesión y mucha angustia, por eso su prudencia se sobresalta ante la explicación del doctor, pues supone reconfigurar su idea del riesgo y le confronta al hecho de que el peligro y su gestión no es una realidad absoluta sino construida, precaria y mutable. Es más, Frederik ve sacudida la conducta que considera moralmente aceptable: practicar 
sexo seguro (esto es, sexo con preservativo) está bien y practicar sexo de riesgo, mal: "Se da cuenta de lo que... ¿Qué dirían sus colegas?...", le espeta al doctor. Como en la vista cenital de la imagen $n^{\circ} 2$, sobre todo encuentro médico-paciente sobrevuela el conocimiento vinculado a la amenaza y al riesgo: la ideología acerca del contagio del virus del sida $y$, en realidad, acerca de cualquier hecho patológico ejerce su peso aplastante sobre las informaciones y las decisiones corporales.

Los meses pasan y Frederik acaba por aceptar e incorporar la nueva lectura sobre el riesgo que le proporciona la medicina, que sin embargo no es más que otra construcción del especialista, que interminablemente produce saber y lo divulga, condicionando a cada paso la generación de subjetividades: "Por primera vez alguien informado y a quien le importaba, alguien que tenía todas las cartas, me había dado una acertada imagen de nosotros mismos", dice Frederik en un gesto que aúna el sometimiento al poder difuso del doctor, la gratitud y cierto alivio ingenuo, y que es perfectamente representativo de cómo funciona la tecnología del yo basada en el riesgo médico y la prudencia.

La conciencia permanente del peligro en la esfera personal genera, como en el caso de Frederik, momentos de angustia que desempeñan un papel fundamental en la toma de decisiones, a favor de la prudencia. El sentimiento de ansiedad es vital para el mantenimiento del orden. EI individuo hipervigilante de su entorno, el sujeto obsesionado por detectar a tiempo los peligros que le acechan, es una presencia emergente de la sociedad del riesgo. El cuento de Kafka titulado "La guarida" (2004) ejemplifica bien la nueva subjetividad de la hipervigilancia. Trata de un animal que ha construido con todo su empeño una madriguera en la que poder vivir seguro. Pese a que la construcción es prácticamente infranqueable y pese a que el animal se desvive por protegerse, su angustia nunca llega a desaparecer. "He terminado la guarida y parece que ha quedado bien", dice al inicio del relato el animal, y enseguida prosigue: "Es tan segura como puede haber algo seguro en este mundo" (ibídem: 610), lo que no excluye que, en su neurosis, siempre encuentre un peligro potencial que atenta contra su calma: "Yo vivo en paz en el interior de mi guarida y, mientras tanto, el enemigo horada lentamente y en silencio desde algún lugar para llegar hasta donde yo estoy" (ibídem: 611). 
El sosiego es momentáneo en la sociedad del riesgo. La ideología de la salud nos proporciona información y nos reclama que, teniéndola en cuenta, nos responsabilicemos del bienestar de nuestro cuerpo, en el presente pero también en el futuro. Ese mandato, sin embargo, es infinito y frustrante porque, de un lado, los riesgos no hacen más que multiplicarse $y$, de otro lado, carecemos de una instancia a la que apelar para el caso de que, habiéndose seguido las pautas prescritas por la prudencia, la amenaza finalmente se materialice y el daño se produzca.

\section{EL INDIVIDUO HIPERVIGILANTE EN LOS CUENTOS DE LYDIA DAVIS}

La subjetividad hipervigilante, que empieza a estar consolidada en las producciones culturales contemporáneas, se ilustra bien mediante la obra narrativa de Lydia Davis (nacida en 1947 en Massachusetts). Sus cuentos están poblados de personajes atemorizados por peligros diversos, hipervigilantes y obsesionados con las prácticas prudentes. Véase, en ese sentido, el inicio de uno de sus relatos más conocidos, "Los temores de la señora Orlando":

"El mundo de la señora Orlando es oscuro. Conoce los peligros de su casa: la estufa de gas, las escaleras empinadas, la bañera resbaladiza y distintos cables eléctricos en mal estado. Fuera de su casa sabe de ciertos peligros, pero no de todos, y su propia ignorancia la asusta, ávida de información sobre crímenes y desastres.

Aunque tome las precauciones posibles, ninguna precaución será suficiente. Procura estar preparada para una hambruna imprevista, para el frío, el aburrimiento y las hemorragias. Jamás le falta un esparadrapo, un imperdible y una navaja. En el coche tiene, entre otras cosas, un trozo de cuerda y un silbato, además de una historia social de Inglaterra para leerla mientras espera a sus hijas, que suelen pasar mucho tiempo de compras.

En general, le gusta que los hombres la acompañen: ofrecen protección tanto por su gran envergadura como por su visión racional del mundo. La señora Orlando admira la prudencia y respeta al hombre que reserva una mesa por adelantado, y también al que duda antes de contestar alguna de sus preguntas. Confía en los abogados y se siente comodísima cuando habla con abogados, puesto que la ley respalda cada una de sus palabras." (Davis, 2011: 7). 
La señora Orlando ejemplifica bien el punto de partida de la subjetividad hipervigilante: está extraordinariamente pendiente de los peligros que la rodean y además está asustada ante aquellos peligros que sabe que existen pero que aún desconoce; toma precauciones para paliar las calamidades que pudieran sucederle, pero tiene la certeza de que en todo caso serán insuficientes; valora la prudencia como una cualidad sobresaliente y anhela una existencia segura. En otros relatos de Davis, hay personajes atemorizados que viven en un mundo que perciben como pernicioso, sin ser capaces de entender con lucidez las amenazas que sufren y sin poder abandonar su estado de alerta. Es el caso del microrrelato "En una casa sitiada", cuyo texto completo es este:

\begin{abstract}
"En una casa sitiada vivían un hombre y una mujer. Encogidos de miedo en un rincón de la cocina, el hombre y la mujer oían pequeños estampidos. "El viento", decía la mujer. "Cazadores", decía el hombre. "La lluvia", decía la mujer. "El ejército", decía el hombre. La mujer quería irse a casa, pero ya estaban en casa, allí, en mitad del campo, en una casa sitiada." (ibídem: 66).
\end{abstract}

El hombre y la mujer de ese cuento son reformulaciones del animal de la madriguera de Kafka. En su casa levantada en mitad del campo, cualquier pequeño ruido puede ser una amenaza para la que no hay escapatoria. Y ese mismo es el tema de "Desastre natural", que se inicia así:

"No resistiremos mucho más aquí, en nuestra casa, a orillas del mar crecido. El frío y la humedad acabarán con nosotros, porque ya no es posible irse: el frío ha agrietado la única carretera que teníamos." (ibídem: 182).

La ansiedad que caracteriza al individuo hipervigilante es un mal endémico, algo así como una enfermedad reinante en la sociedad, que por ello puede hacerse cargo del estado de angustia. La comunidad, cuyos miembros padecen terrores semejantes, es comprensiva y da por ello cierto consuelo al individuo atormentado como se recoge en el cuento "Miedo":

"Casi todas las mañanas, cierta mujer de nuestra comunidad sale corriendo de su casa con la cara blanca y el abrigo ondeante, alborotado. Grita, "Emergencia, emergencia", y alguno de nosotros corre y la coge hasta que se calman sus miedos. Sabemos que finge; no le ha sucedido nada en realidad. Pero la entendemos, porque raro sería encontrar a uno de nosotros que alguna vez no se haya visto movido a 
hacer exactamente lo que ella ha hecho, y cada vez hemos necesitado recurrir a toda nuestra fuerza, e incluso a la fuerza de nuestros amigos y familiares, para tranquilizarnos." (ibídem: 261).

Y es que los peligros residen en lo mínimo, capaces de quebrar la paz en cualquier momento. Así sucede en el cuento "La espina", que trata sobre un peligro miserable: a un hombre se le clava en la garganta una espina del pescado:
“Una noche, sin embargo, preparé para cenar filetes de pescado. En teoría, los filetes no tenían espinas, pero en uno debía de haber quedado una espina pequeña porque mi marido se la tragó. Se le clavó en la garganta. Era algo que nunca nos había pasado a ninguno de los dos, aunque la posibilidad nos preocupara siempre. Le di pan, se bebió muchos vasos de agua, pero la espina estaba bien hincada, y no se movia." (ibídem: 72).

Ni siquiera puede uno relajarse ante lo más inocente. Hasta en aquello que ofrece garantías teóricas de no ser peligroso (el pescado sin espinas) encuentra el individuo hipervigilante razones para intranquilizarse. De hecho, su inquietud recibe confirmación y sentido cuando llega el día en que el mal augurio se cumple y se comprueba que había razones para tener miedo: después de todo, había una espina en el filete de pescado sin espinas. Por eso hay sujetos que no se limitan a estar asustados, sino que se implican en la prevención de peligros y en una búsqueda activa del bienestar. Es en ese punto donde el saber médico introduce su conocimiento, en formato más o menos divulgado, y donde el mercado muestra sus productos vinculados a la promoción de la salud. El individuo hipervigilante dispone, gracias a ambas instancias, de recomendaciones y recursos para intentar paliar los riesgos. Da un paso al frente a partir del miedo o de la conciencia del peligro y se postula como agente de su bienestar, como un actor informado y esmerado en el cuidado del cuerpo. Así sucede con el personaje de Wassilly, que intenta mejorar su condición corporal a través de prácticas saludables (hace yoga, come yogur, toma el sol), que incorpora a su vida siguiendo consejos expertos. A diferencia de los personajes de los relatos anteriores, Wassilly recurre a libros en busca de herramientas que potencien su salud y de un saber nuevo con el que empieza a pensar su cuerpo y sus conductas en términos de vitaminas, de proteínas, etc. 
Emerge en Wassilly, tras adquirir conciencia de su vulnerabilidad, la nueva subjetividad:

\begin{abstract}
"[Wassilly] No admitió su creciente fragilidad hasta el día en que su hermana se presentó a verlo cuando estaba en cama, víctima de una dolorosa sinusitis, y, brusca como siempre, le dijo que nunca había conocido a nadie que se pusiera enfermo tan a menudo.
\end{abstract}

Después de aquello, hizo yoga durante algún tiempo, y todas las mañanas practicaba la postura de la vela, que, según el manual, "despejaba los senos nasales y a la vez redistribuía el peso". (La asistenta se lo encontraba así, mirándose un pliegue del estómago, con el mentón clavado en la tiroides).

Tomó la decisión de comer más razonablemente y adoptar el yogur como principal fuente de proteínas.

La vitamina $\mathrm{D}$, decía otro de los libros que consultó, era la vitamina más difícil de obtener por medios naturales, y se formaba en la grasa de la piel gracias a los rayos solares entre las diez y las dos de la tarde, de mayo a septiembre, en los países occidentales (en el hemisferio norte). Así que, el 1 de mayo, por la mañana Wassilly expuso la mayor parte de su piel a un sol débil, y se tumbó en el jardín, tiritando, media hora, hasta que no aguantó más y se rindió. Más tarde, en verano, decidió combinar la postura de la vela y los baños de sol." (ibídem: 87-88)

Wassilly va fragmentándose en piezas que merecen atención independiente: es al enfermar de sinusitis cuando empieza a practicar yoga, para despejar sus senos nasales, ejercitándose en una postura que le obliga a mirarse un pliegue en el estómago, a clavar el mentón en la glándula tiroidea; es al preocuparse por la vitamina $D$ de la que dispone su cuerpo cuando se hace consciente de la grasa de la piel, lugar donde se ha de fabricar la vitamina. En definitiva, el individuo se percata de su fragmentación, compone el mapa de riesgos de su cuerpo, y se da cuenta de cómo cada uno de sus fragmentos, en peligro particular, puede conmocionar al conjunto, que siempre es un objeto compuesto en su precariedad. En una experiencia cercana a la de Wassilly, la protagonista del "Diario de la tiroides" accede al conocimiento de la medicina, que le trasmite, divulgado, su asistente sanitaria, y lo pone al servicio de la comprensión de su organismo. Vislumbra su nueva situación e inicia una etapa distinta en la relación con su propio cuerpo, 
que es leído y descompuesto en múltiples pedazos, sometidos uno a uno al dictado de la glándula tiroidea, y que se ralentiza en bloque:
"Mi asistente sanitaria me explicó que la glándula tiroides controla todas las partes del cuerpo: no sólo el cerebro, sino también el corazón, la digestión, el metabolismo, la circulación, y otras cosas que creo que se me olvidan. En caso de grave hipotiroidismo todo se hace más lento. Tengo el pulso lento, la digestión lenta, la mente lenta quizá, la temperatura baja, las manos y los pies fríos. A veces tengo cincuenta pulsaciones por minuto, o menos aún. No sabía para qué sirve la tiroides. Ahora he averiguado que es tan importante que, de continuar funcionando a tan bajo nivel, me moriría: me moriría pronto, quiero decir. Nunca me había sentido unida a una parte tan sorprendente del cuerpo como la glándula tiroides, y me siento como si mi cuerpo se hubiera vuelto de repente un extraño, o como si la extraña fuera yo misma." (ibídem: 387-388).

No todo sujeto hipervigilante reacciona contra el peligro activamente, sino que en ocasiones se opta por la abstinencia, por renunciar a acciones que, aun siendo placenteras, esconden riesgos. Paradójicamente, mientras que la sociedad liberal valora el riesgo asumido por empresarios y emprendedores (Sloterdijk, 2007: 67-71), condena a quienes asumen riesgos innecesarios y son imprudentes con su salud. Como el animal de Kafka, que sabe que su seguridad le exige prescindir del mundo exterior, tan querido, "al suelo, los árboles, el aire" (Kafka, 2004: 627), los personajes de Davis dejan de comer aquellos alimentos que alguna instancia médica o sanitaria con autoridad ha asociado a ciertos riesgos como en los cuentos "Carne, mi marido" o "Comer pescado sola". En el universo de valores de esos personajes, "la ociosidad despreocupada del hedonismo retrocede a medida que cada cual se convierte en agente autónomo e informado" (Lipovetsky, 2007: 231):

"Con frecuencia le preparo comidas sin carne porque creo que la carne no nos sienta bien. Y tampoco les pongo mariscos, porque la mayoría de los mariscos tampoco nos sientan bien, y casi nunca llevan pescado, en parte porque no me acuerdo de qué clases de pescado pueden comerse sin ningún tipo de riesgo y cuáles no, casi con absoluta seguridad, pero principalmente porque sólo le gusta el pescado si se lo sirven en un restaurante, o guisado de manera que no se dé cuenta de que es pescado. Tampoco solemos comer queso, por los problemas con la grasa. Le preparo una cazuela de arroz 
integral, por ejemplo, o verduras de invierno con salsa de perejil, o sopa de nabos con hojas de nabo." (Davis, 2011: 147148).

"Amo el pescado, pero muchos pescados no deberían comerse más, y se ha vuelto difícil saber cuáles pescados puedo comer. Llevo en mi billetera una pequeña lista plegada distribuida por la Audubon Society, que advierte cuáles pescados evitar, cuáles pescados comer con precaución y cuáles pescados comer sin restricciones. Cuando como con otra gente no saco esta lista de la billetera, porque no es muy divertido comer con alguien que saca una lista como esta de su billetera antes de pedir la comida. Simplemente me arreglo sin ella, aunque generalmente solo puedo recordar que no debo comer salmón de granja o salmón salvaje, excepto por el salmón salvaje de Alaska, que no aparece nunca en el menú." (Davis, 2014: 57)

El dominio de las autoridades sanitarias, alimentarias $y$, en general, científicas, tiene una faceta más en la incontestabilidad efectiva de los argumentos estadísticos. Así, pocas razones tienen más peso para el individuo hipervigilante que la estadística, que indica de un modo presuntamente objetivo cuál es el camino hacia una vida más sana, más larga, mejor. Hallamos en este punto la incorporación plena del razonamiento de tipo actuarial en la gestión de los asuntos del cuerpo. En ese contexto debe leerse el microrrelato paródico "Los resultados de un estudio estadístico", cuyo texto completo es este:

"Las personas que eran más concienzudas

como niños

vivian más años." (ibídem: 230).

Y eso sucede también en el relato "Helen y Vi: un estudio sobre la salud y la vitalidad", en el que la autora se hace con la retórica de la promoción de la salud y aborda distintos aspectos de la vida, las costumbres, las aficiones, etc. de dos ancianas, en busca del secreto de su longevidad, y que plantea en el fondo una mirada ácida sobre el cálculo estadístico del saber que divulga la medicina. El texto tiene el estilo del breve fragmento que sigue:

"Aunque la herencia genética, sin duda, desempeñe un papel en la salud y longevidad del individuo, no es disparatado concluir que ciertos rasgos comunes a las biografías de Vi y de Helen, a su personalidad y costumbres, han contribuido a su longevidad y buena salud." (Davis, 2011: 690). 
No tienen espacio, en la producción de Davis, los individuos que se resisten a pensarse en términos de riesgo, los refractarios a la lógica actuarial. En sus historias mínimas, la gente corriente sufre preocupaciones y miserias cotidianas, y acata como puede las directrices de la ideología de la salud imperante, sin llegar a plantearse prácticas contestatarias o subversivas. No hay crítica ni ironía en los personajes de Davis, sino naturalización de una forma nueva de pensar la existencia, que no garantiza a fin de cuentas la tranquilidad, pero parece responder al sentido común. Sus reacciones al miedo o a la amenaza son diversas, y encuentran en el saber de los especialistas sanitarios recetas para entender su cuerpo y hacerse cargo de él. En su grado más sofisticado, el autogobierno implica recurrir a saberes generados mediante recursos de tipo actuarial, a los que se concede un crédito particular. En el mundo de Davis no hay cabida para héroes como los de Los hechizados, la novela de Gombrowicz en la que la pareja protagonista asume su vampirismo, renuncia dichosamente a la sanación-salvación y acepta el contagio $y$, por ende, el estigma, el alejamiento e incluso la maldad a la que tal vez el hechizo obligue. No tienen tampoco cabida actuaciones como la de Aleksei Ivanovich, protagonista de El jugador de Dostoyevski (1980), que busca el premio y la salvación "arriesgando más que la vida; me atreví a arriesgar... y me pude contar de nuevo entre los hombres" (ibidem: 172). No hay rebeldía en el horizonte de expectativas de los personajes de Davis, como tampoco hay emancipación posible, porque nunca late el deseo de ella y porque su lugar está invadido por un deseo de seguridad que es, además, bien comprendido, acogido y auxiliado por el conjunto de la comunidad.

\section{BiBLIOGRAFÍA}

Beck, U. (2002). La sociedad del riesgo global. Madrid: Siglo XXI.

Castel, R. (1991). From dangerous to risk. En G. Burchell, C. Gordon y P. Miller (Eds.). The Foucault effect: Studies in governmentality (pp. 281298). Chicago: The University of Chicago Press.

Crawford, R. (1980). Healthism and the Medicalization of Everyday Life. International Journal of Health Services, 10(3), 365-388.

Davis, L. (2011). Cuentos completos. Barcelona: Seix Barral.

Davis, L. (2014). Ni puedo ni quiero. Buenos Aires: Eterna Cadencia. 
Dawes, R., Faust, D., y Meehl, P. (1989). Clinical Versus Actuarial Judgment. Science, 243(4899), 1668-1674.

De Marinis, P. (1999). Gobierno, Gubernamentalidad, Foucault y los Anglofoucaultianos. Un Ensayo sobre la Racionalidad Política del Neoliberalismo. En F. García y R. Ramos (Eds.). Retos Actuales de la Teoría Social: Globalidad, Reflexividad y Riesgo (pp. 73-103). Madrid: Centro de Investigaciones Sociológicas.

Defossez, E. (2016). Health and personal responsibility in the context of neoliberalism: Cultivating alertness, autonomy and accountability through three contemporary health practices. The International Journal of Communication and Health, 9, 73-79.

Deleuze, G. (1999). Post-scriptum sobre las sociedades de control. En Conversaciones 1972-1990 (pp. 272-286). Valencia: Pre-textos.

Dostoyevski, F. (1980). El jugador. Barcelona: Alianza.

Ericson, R., y Haggerty, K. (1997). Policing the Risk Society. Oxford: Clarendon.

Ewald, F. (1986). L'Etat Providence. París: Grasset \& Fasquelle.

Ewald, F. (1991). Insurance and risk. En G. Burchell, C. Gordon y P. Miller (Eds.). The Foucault effect: Studies in governmentality (pp. 197-210). Chicago: The University of Chicago Press.

Feeley, M., y Simon, J. (1994). Actuarial Justice: The Emerging New Criminal Law. En D. Nelken (Ed.). The Futures of Criminology (pp. 173-201). Londres: Sage.

Førde, O. (1998). Is imposing risk awareness cultural imperialism? Social Science E Medicine, 47(9), 1155-1159.

Foster Wallace, D. (2002). La broma infinita. Barcelona: Mondadori.

Foucault, M. (1990). Tecnologías del yo. Barcelona: Paidós.

Foucault, M. (2006). Seguridad, territorio, población. Buenos Aires: Fondo de Cultura Económico.

Foucault, M. (2009). Nacimiento de la biopolítica. Madrid: Akal.

Garland, D. (2003). The Rise of Risk. En R. Ericson y A. Doyle (Eds.). Risk and Morality (pp. 48-86). Toronto: University of Toronto.

Garland, D. (2005). La cultura del control. Crimen y orden social en la sociedad contemporánea. Barcelona: Gedisa.

Giddens, A. (2000). Un mundo desbocado. Los efectos de la globalización en nuestras vidas. Madrid: Taurus. 
Gombrowicz, W. (2003). Los hechizados. Barcelona: Seix Barral.

Harcourt, B. (2007). Against Prediction. Profiling, Policing, and Punishing in an Actuarial Age. Chicago: University of Chicago Press.

Kafka, F. (2004). Cuentos completos. Madrid: Valdemar.

Katz, C. (2001). The State Goes Home: Local Hyper-Vigilance of Children and the Global Retreat from Social Reproduction. Social Justice, 28(3): 47-56.

Liede, A., Karlan, B., y Narod, S. (2004). Cancer Risks for Male Carriers of Germline Mutations in BRCA1 y BRCA2: A Review of the Literature. Journal of Clinical Oncology, 22(4), 735-742.

Lipovetsky, G. (2007). La felicidad paradójica. Barcelona: Anagrama.

Logan, W. (2000). A Study in 'Actuarial Justice': Sex Offender Classification Practice and Procedure. Buffalo Criminal Law Review, 3(2): 593-637.

Lupton, D. (1993). Risk as Moral Danger: The Social and Political Functions of Risk Discourse in Public Health. International Journal of Health Services, 23(3), 425-435.

Lyng, S. (1990). Edgework: A Social Psychological Analysis of Voluntary Risk Taking. American Journal of Sociology, 95(4), 851-886.

Lyng, S. (Ed.) (2005). Edgework. The Sociology of Risk-Taking, Nueva York: Routledge.

Mary, P. (2001). Pénalité et gestion des risques: vers une justice 'actuarielle' en Europe. Déviance et Société, 25(1), 33-51.

Massé, R. (1999). La santé publique comme nouvelle moralité. En P. Fortin (Dir.). La réforme de la santé au Québec (pp. 155-174). Montreal: Fides.

Méndez Guédez, J. C. (1999). El libro de Esther. Madrid: Lengua de Trapo.

Mujica, J. (1992). Coloring the Hazards: Risks Maps Research and Education to Fight Health Hazards. American Journal of Industrial Medicine, 22, 767-770.

Nettleton, S. (1997). Governing the risky self. How to become healthy, wealthy and wise. En R. Bunton y A. Petersen (Eds.). Foucault, Health and Medicine (pp. 207-222). Londres: Routledge.

O'Malley, P. (1996). Risk and responsibility. En A. Barry, T. Osborne y N. Rose (Eds.). Foucault and political reason. Liberalism, neo-liberalism and rationalities of government (pp. 189-207). Londres: University College London Press.

O'Malley, P. (Ed.) (1998). Crime and the Risk Society. Aldershot: Dartmouth. 
Peeters, F. (2004). Pildoras azules. Bilbao: Astiberri.

Petersen, A., y Lupton, D. (1996). The New Public Health. Health and Self in the Age of Risk. Londres: Sage.

Piantadosi, S., Byar, D., y Green, S. (1988). The Ecological Fallacy. American Journal of Epidemiology, 127(5), 893-904.

Reddy, S. (1996). Claims to expert knowledge and the subversion of democracy: the triumph of risk over uncertainty. Economy and Society, 25(2), 222-254.

San Martín, D. (2009). El riesgo como dispositivo de gobierno en la sociedad de control. Algunas notas sobre Frontex. En J. Á. Brandariz, A. Fernández de Rota y R. González (Coords.). La globalización en crisis. Gubernamentalidad, control y politica de movimiento (pp. 51-68). Málaga: Universidad Libre Experimenal y Universidade Invisíbel.

Sepúlveda, M. (2011). El riesgo como dispositivo de gobierno: neoprudencialismo y subjetivación. Revista de Psicología, 20(2), 103124.

Sharon, T. (2014). Healthy Citizenship beyond Autonomy and Discipline: Tactical Engagements with Genetic Testing. BioSocieties, 10(3), 295316.

Skolbekken, J.-A. (1995). The risk epidemic in medical journals. Social Science $\in \mathrm{M}$ Medicine, 40(3), 291-305.

Sloterdijk, P. (2007). En el mundo interior del capital. Para una teoría filosófica de la globalización. Madrid: Siruela.

Smyk, D., Rigopoulou, E., Baum, H., Burroughs, A., Vergani, D., y Bogdano, D. (2012). Autoimmunity and Environment: Am I at risk? Clinical Reviews in Allergy and Immunology, 42, 199-212.

Turrini, M. (2015). A genealogy of 'healthism': Healthy subjectivities between individual autonomy and disciplinary control. Eä - Journal of Medical Humanities $\in$ Social Studies of Science and Technology, 7(1), 11-26. 